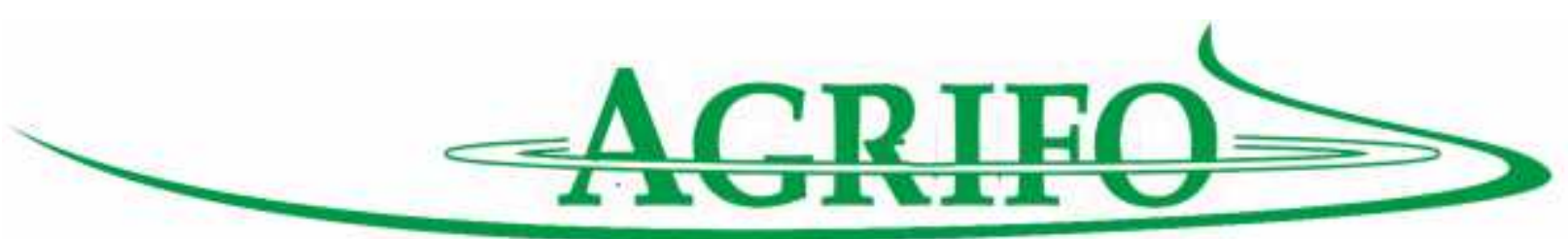

\title{
ANALISIS SWOT STRATEGI PEMBERDAYAAN MASYARAKAT PROGRAM PENATAAN LINGKUNGAN PERMUKIMAN KOMUNITAS DI KELURAHAN SURYATMAJAN, KOTA YOGYAKARTA
}

\author{
Nurasih Shamadiyah ${ }^{1}$
}

\section{Email Author: nurasih@unimal.ac.id}

\begin{abstract}
Community empowerment has wide meaning from various point of view. Community empowerment is the emphasis on the behavior of self-sustaining local communities as a system that breaks down themselves. Communities have the right to determine strategies for empowerment strategies according to their strengths, weaknesses, opportunities, and threats. Analysis of empowerment strategies through SWOT analysis for strategies that can be in accordance with the characteristics of society. This research was conducted at the priority location of Community Based Settlement Environment (PLPBK) program of Kelurahan Suryatmajan with number of informant 30 people and sampling technique using snowball sampling to find an information. From the analysis result, based on aformentioned reasons there are 4 segments of community empowerment point in the priority areas, namely handicraft and food industry, ecogreen area, green open space area, and river arrangement. The determination of community empowerment strategy is the initial stage of overall empowerment activities, because the initial stage can determine the category of society and the pattern of empowerment to be undertaken
\end{abstract}

\footnotetext{
${ }^{1}$ Staff Pengajar Fakultas Pertanian Universitas Malikussaleh
} 


\section{PENDAHULUAN}

Pemberdayaan dapat diartikan sebagai upaya untuk memberikan daya (empowerment) atau kekuatan (strength) kepada masyarakat. Pemberdayaan adalah bagaimana membuat masyarakat mampu membangun dirinya dan memperbaiki kehidupannya sendiri. Istilah mampu disini mengandung makna: berdaya, paham, termotivasi, memiliki kesempatan, melihat dan memanfaatkan peluang, berenergi, mampu bekerja sama, tahu sebagai alternatif, mampu mengambil keputusan, berani mengambil resiko, mampu mencari dan menangkap informasi, serta mampu bertindak sesuai inisiatif (Slamet, 2003). Sumardjo (1999) menyebutkan ciri-ciri warga masyarakat berdaya yaitu mampu memahami diri dan potensinya, mampu merencanakan (mengantisipasi kondisi perubahan kedepan), mampu mengarahkan dirinya sendiri, memiliki kekuaatan untuk berunding, memiliki bargaining power yang memadai dalam melakukan kerjasama yang saling menguntungkan, dan dapat bertanggung jawab atas tindakannya. Pemberdayaan masyarakat titik beratnya adalah penekanan pada pentingnya masyarakat lokal yang mandiri sebagai suatu sistem yang mengorganisir diri mereka sendiri. Pendekatan pemberdayaan masyarakat yang demikian diharapkan dapat memberi peranan kepada individu bukan sebagai obyek, tetapi justru sebagai subyek pelaku pembangunan yang ikut menentukan masa depan dan kehidupan masyarakat secara umum (Setiana, 2005).

Tujuan yang ingin dicapai dari pemberdayaan masyarakat adalah untuk membentuk individu dan masyarkat menjadi mandiri. Kemandirian tersebut meliputi kemandirian berpikir, bertindak dan mengendalikan apa yang mereka lakukan. Kemandirian masyaraka merupakan suatu kondisi yang alami oleh masyarakat yang ditandai dengan kemampuan memikirkan, memutuskan serta melakukan Sesutu yang dipandang tepat demi mencapai pemecahan masalah yang dihadapi dengan mempergunakan daya atau kemampuan yang dimiliki (Sulistiyani, 2004).

Program Penataan Lingkungan Permukiman Komunitas merupakan salah satu program yang bertujuan untuk mewujudkan perbaikan kualitas hidup masyarakat miskin melalui penataan lingkungan permukiman yang teratur, aman, dan sehat. Program ini merupakan program penataan lingkungan padat, kumuh dan miskin pada suatu wilayah/kawasan yang direncanakan dan dibangun dengan pendekatan partisipatif antara masyarakat dengan pemerintah daerah. PLPBK lahir sebagai suatu model pembangunan yang berbasis komunitas, artinya melibatkan masyarakat secara langsung.

Gagasan perubahan sosial tersebut juga dalam rangka mengubah pemikiran, sikap dan perilaku masyarakat dengan tujuan $\mathrm{m}$ eningkatkan kualitas hidup, sekaligus supaya untuk menata organisasi guna membangun kepercayaan secara luas. Adanya kepercayaan tersebut diharapkan masyarakat mampu mendorong dukungan dari berbagai pihak, termasuk di dalamnya dukungan sumberdana yang potensial. Sehingga cita-cita tatanan masyarakat menuju masyarakat madani dapat terwujud (Pedoman Teknis PLPBK, 2014).

Tata guna lahan Kelurahan Suryatmajan didominasi oleh fungsi perkantoran seluas $7 \mathrm{Ha}$, perdagangan dan jasa seluas $3 \mathrm{Ha}$, dan permukiman seluas 13 Ha. Kondisi topografi 
Kelurahan Suryatmajan sangat bervariasi dengan kemiringan berkisar 2 - 19\%. Pada kawasan sebelah barat cenderung datar dan mulai curam di sisi timur jalan Mataram sampai pada titik terendah di area sempadan sungai Code dan bibir sungai Code. Perbedaan ketinggian antara jalan Mataram dengan bibir sungai Code berkisar 6 - $11 \mathrm{M}$. Kelurahan Suryatmajan berada di kawasan strategis pemerintahan provinsi, perdagangan, jasa, dan pariwisata utama Kota Yogyakarta, yaitu Malioboro dan Keraton Kesultanan Yogyakarta. Berdekatan dengan hotel-hotel besar seperti Inna Garuda, Ibis, Mutiara, maupun penginapan-penginapan kecil di daerah Kampung Sosrokusuman. Proses pemberdayaan masyarakat diarahkaan pada pengembangan sumber daya alam dan sumber daya manusia yang ada dilingkungannya agar dapat menciptakan peluang usaha yang sesuai dengan yang mereka miliki.

\section{METODOLOGI PENELITIAN}

Metode yang digunakan dalam penelitian ini ialah metode analisis deskriptif kualitatif menggunakan SWOT. Analisis SWOT adalah evaluasi terhadap keseluruhan kekuatan, kelemahan, peluang, dan ancaman. Analisis SWOT terdiri atas lingkungan pemasaran internal dan eksternal (Kottler dan Keller, 2006). Deskriptif kualitatif berarti menggambarkan apa yang terjadi di lapangan sesuai dengan fakta yang ada, yang kemudian diinterpretasikan ke dalam sebuah analisis. Metode penentuan lokasi dilakukan secara purposif, yaitu di Kelurahan Suryatmajan, Kecamatan Danurejan, Kota Yogyakarta karena kawasan ini merupakan kawasan yang menjadi percontohan program PLPBK. Metode pengambilan informan dilakukan dengan metode snowball sampling. Metode ini digunakan karena dalam penelitian ini bertujuan untuk menganalisis strategi pemberdayaan masyarakat, sehingga jawaban wawancara dari pertanyaan yang diajukan diasumsikan akan memiliki persamaan dan perbedaan. Jika terdapat persamaan strategi maka jumlah informan yang diambil dirasa cukup untuk memenuhi kuota penelitian. Teknik dalam snowball sampling ialah informan pertama yang diwawancara kemudian akan merekomendasikan siapa orang yang akan diwawancara selanjutnya, begitu terus selanjutnya sampai data yang dikumpulkan telah cukup. Informan yang diambil dalam penelitian ini berjumlah 30 orang mewakili kawasan prioritas yang akan dijadikan kawasan percontohan. Penelitian ini menggunakan daftar pertanyaan sebagai panduan untuk mendapatkan data. Data primer didapatkan melalui wawancara dengan informa, sedangkan data sekunder didapatkan melalui studi kepustakaan berupa buku, jurnal, dan artikel.

\section{HASIL DAN PEMBAHASAN}

\section{Gambaran Umum Kawasan Prioritas}

Kelurahan Suryatmajan berada di daerah administratif Kecamatan Danurejan, Kota Yogyakarta, Provinsi Daerah Istimewa Yogyakarta memiliki luas wilayah $0,28 \mathrm{Km}^{2}$ dengan kepadatan penduduk tertinggi kedua setelah Kelurahan Keparakan di Kota Yogyakarta. Kelurahan Suryatmajan berada di $114 \mathrm{Km}$ ketinggian tanah dari permukaan laut (www.jogjaprov.go.id, 2010). Kawasan prioritas PLPBK Kelurahan Suryatmajan terbagi menjadi 4 segmen untuk jangka waktu 5 tahun, yaitu Kampung Gemblakan Atas, Gemblakan Bawah, Cokrodirjan, dan Sosrokusuman. Untuk segmen pertama 
mulai pada Kampung Gemblakan Bawah, meliputi RW 7, RW, 8, dan RW 9 khususnya tepi bantaran sungai Code. Letak kawasan prioritas berada di sepanjang bantaran sungai kode yang melintasi Kelurahan Suryatmajan, dengan akses jalan strategis di jalan Mataram.

Kawasan Kampung Gemblakan Bawah sudah terkenal dengan kulinernya, yaitu kacang bawang dan bebek goreng. Meskipun produk industri kacang bawang dan bebek goreng ini telah beredar di beberapa toko-toko besar dan rumah makan, namun tidak mencantumkan brand sendiri karena sistem jual beli putus kiloan. Toko-toko besar dan rumah makan ini kemudian mengemas dengan brand mereka, padahal tempat produksi di Kampung Gemblakan Bawah. Oleh karena itu, Kampung Gemblakan Bawah dipilih untuk segmen spot kuliner agar industri kecil ini dapat berkembang. Untuk mewujudkan spot kuliner ini tidak hanya dengan mengembangkan usaha, tetapi juga infrastruktur pendukung, sarana dan prasarana serta sumber daya manusia yang handal. Selain industri kuliner, Kampung Gemblakan Bawah juga terdapat tempat produksi kerajinan wayang kulit yang bisa menjadi potensi oleh-oleh khas Kelurahan Suryatmajan. Spot industri kerajinan ini juga masuk pada segmen 1, yaitu spot jajanan dan oleh-oleh.

Pada segmen 2 yaitu Kampung Gemblakan Atas yang mendapatkan penghargaan green and clean serta pengelolaan bank sampah terbaik dari BLH Provinsi DIY. Prestasi lainnya ialah membuat kerajinan dari sampah dan yang terbaru membuat biogas dari sampah organik yang dapat menjadi pengganti gas LPG untuk memasak, bantuan dari BLH dan GIZ. Karena potensi-potensi inilah maka Kampung Gemblakan Atas dipilih sebagai spot eco-green. Segmen 3 berada di kawasan Kampung Cokrodirjan. Kampung ini memiliki potensi kesenian tradisional Jawa, yaitu Bergodo Cokrodirjan atau pasukan kesenian Keraton Kesultanan Yogyakarta. Masyarakat yang tergabung dalam pasukan ini melakukan latihan rutin dengan cara keliling kampung. Kegiatan ini dapat menjadi daya tarik bagi wisatawan maupun masyarakat sekitar yang ingin melihatnya. Agar wisatawan maupun masyarakat dapat nyaman melihat pertunjukan ini maka perlu di tata kawasan lingkungan permukimannya sedemikian rupa. Untuk mendukung kenyamanan ini diperlukan penataan lingkungan permukiman secara komprehensif seperti penataan ruangruang terbuka, penataan sanitasi dan MCK komunal, RTH, dan penataan kerajinan souvenir. Kerajinan souvenir di Kampung Cokrodirjan sudah ada sejak lama, namun perlu di tata kembali agar menambah nilai estetika untuk mendukung kampung wisata bantaran sungai Code. Segmen 3 juga termasuk penataan ruang terbuka di Kampung Sosrokusuman yang selama ini menjadi lahan parkir penunjang Malioboro yang letaknya dekat dengan Hotel Ibis dan Mall Malioboro, maka jika ruang terbuka ini di tata menjadi tempat publik seperti playground, taman lansia, dan perpustakaan, maka akan menambah daya tarik lokasi hotel dan mall. Karenanya penataan ruang terbuka ini memerlukan kemitraan dari pihak swasta maupun pemerintah kota/provinsi. Sedangkan Kampung Ledok Macanan masuk ke dalam segmen 4, yaitu penataan kawasan pemukiman bantaran sungai serta pengadaan ruang terbuka hijau.

\section{Analisis SWOT Strategi Pemberdayaan Masyarakat}


Analisis SWOT adalah didasarkan pada hubungan atau interaksi antara unsur-unsur internal, yaitu kekuatan dan kelemahan, terhadap unsur-unsur eksternal yaitu peluang dan ancaman. Petunjuk umum yang sering diberikan untuk perumusan adalah memanfaatkan kesempatan dan kekuatan (O dan $\mathrm{S}$ ). Analisis ini diharapkan membuahkan rencana jangka panjang. Mengatasi atau mengurangi ancaman dan kelemahan ( $\mathrm{T}$ dan W). Analisa ini lebih condong menghasilkan rencana jangka pendek, yaitu rencana perbaikan (short-term improvement plan). Tahap awal proses penetapan strategi adalah menaksir kekuatan, kelemahan, kesempatan, dan ancaman yang dimiliki organisasi (Rangkuti, 2013).

Berdasarkan dokumen pemetaan swadaya (PS) dan observasi di lapangan, berikut faktor-faktor kunci dan internal (Kekuatan dan Kelemahan) dan eksternal (Peluang dan Ancaman) kawasan prioritas Kelurahan Suryatmajan:

\section{a. Kekuatan (Strengths)}

Merupakan kondisi kekuatan yang terdapat di dalam masyarakat Kelurahan Suryatmajan, antara lain:

1) Terdapat beberapa titik untuk ruang terbuka hijau.

2) Terdapat industri rumah tangga baik makanan maupun kerajinan.

3) Aktivitas industri rumah tangga yang dilakukan ibu-ibu dapat berpotensi masuknya programprogram pemberdayaan perempuan dalam sektor ekonomi.

4) Terdapat sumber daya manusia yang memiliki keahlian yang telah disertifikasi dalam bidang pengolahan sampah menjadi kerajinan dan kerajinan batik jumputan.

5) Kelurahan Suryatmajan sering mengikuti pameran yang menampilkan kerajinan daur ulang sampah.

\section{b. Kelemahan (Weakness)}

Merupakan kondisi kelemahan yang terdapat di dalam masyarakat Kelurahan Suryatmajan, antara lain:

1) Kepadatan penduduk yang sangat tinggi.

2) Ruang terbuka hijau kurang tertata dengan baik

3) Tidak ada area bermain anak, sehingga anak-anak banyak bermain di sungai atau jalan pemukiman.

4) Jalan di tepi bantaran sungai terlihat kumuh karena banyak barang-barang yang tidak tertata rapi di depan rumah.

5) Belum ada septictank komunal, limbah rumah tangga langsung terbuang ke sungai.

6) Belum ada sistem pengolahan sampah.

7) Belum ada sistem pengelolaan sampah, sehingga masyarakat masih sering membuang sampah langsung ke sungai.

8) Kerajinan rumah tangga kurang berkembang, belum dipasarkan lebih lanjut.

9) Adanya beberapa titik kerusakan pada talud pemukiman dan talud.

10) Sistem drainase dan sanitasi belum berfungsi dengan baik sehingga mengakibatkan genangan air di pemukiman warga.

11) Kerusakan jalan menuju pemukiman menyebabkan genangan air dan terlihat kumuh. 


\section{c. Peluang (Opportunities)}

Merupakan kondisi peluang masyarakat Kelurahan Suryatmajan yang akan berkembang di masa yang akan datang, antara lain:

1) Keberadaan kawasan prioritas yang dekat dengan kawasan wisata Malioboro, memungkinkan kawasan ini dapat menjadi kawasan penunjang wisata Kota Yogyakarta.

2) Letak kawasan prioritas dekat dengan kawasan perdagangan yang ramai, Jalan Mataram.

3) Kelurahan Suryatmajan berada di tepi Jalan Mataram yang merupakan lokasi strategis, yang dapat dimanfaatkan untuk memaksimalkan pemasaran Kawasan.

4) Beberapa wisatawan baik dalam maupun luar negeri kerap berjalan-jalan di bantaran sungai kawasan prioritas.

5) Adanya tempat produksi industri makanan dan kerajinan yang potensial untuk dikembangkan.

\section{d. Ancaman (Treaths)}

Merupakan kondisi yang dapat mengancam masyarakat Kelurahan Suryatmajan dari lingkungan luar, antara lain:

1) Banyak lahan masyarakat yang sudah dibeli oleh pengembang dari luar yang kemungkinan akan dibangun industri jasa atau perdagangan.

2) Persaingan dengan industri kerajinan atau makanan lain, karena dekat dengan kawasan wisata dan perdagangan, sehingga memerlukan strategi untuk meningkatkan kualitas produk yang dihasilkan.
3) Saluran drainase kota yang menyebabkan genangan di pemukiman warga.

4) Bencana banjir lahar dingin ketika musim hujan dan bencana kebakaran.

Data yang terkumpul mengenai faktor-faktor internal tersebut merupakan potensi di dalam melaksanakan usaha yang direncanakan. Disamping itu perlu diperhatikan faktor-faktor eksternal yang akan dihadapi yaitu peluang-peluang atau kesempatan yang ada atau yang diperhatikan akan timbul dan ancaman atau hambatan yang diperkirakan akan muncul dan mempengaruhi usaha yang dilakukan. Berdasarkan analisis SWOT kawasan prioritas Kelurahan Suryatmajan, maka dapat dirumuskan strategi-strategi sebagai berikut:

\section{a. Strategi SO (Strengths}

Opportunities) yaitu strategi yang disusun dengan memanfaatkan kekuatan Kelurahan Suryatmajan untuk mengembangkan kawasan prioritas di masa yang akan dating. Strategi SO (Strengths Opportunities) antara lain:

1) Penataan ruang terbuka hijau untuk menunjang wisata kawasan bantaran sungai.

2) Mengembangkan industri kerajinan dan makanan menjadi lebih baik, sehingga dapat bersaing dengan produk lainnya dari luar Kelurahan Suryatmajan.

3) Dengan sumber daya manusia yang memiliki keahlian kerajinan dan makanan, maka dapat dibuat workshop pengolahan kacang bawang, kerajinan daur ulang sampah, dan kerajinan wayang kulit untuk para wisatawan. 
4) Menjadikan kampung-kampung di Kelurahan Suryatmajan menjadi beberapa titik sentra seperti sentra kuliner kacang bawang (Gemblakan Bawah), sentra green and clean (Gemblakan Atas), sentra kesenian (Cokrodirjan).

b. Strategi ST (Strengths - Treaths) yaitu strategi yang disusun dengan memanfaatkan kekuatan kawasan prioritas Kelurahan Suryatmajan untuk menghadapi hambatan ataupun ancaman di masa yang akan datang. Strategi ST (Strengths Treaths) antara lain:

1) Pengembang yang membeli tanah turut serta dalam penataan ruang terbuka hijau, agar rencana pengembangan kawasan baru agar dapat sesuai dan tidak tumpangtindih dengan program penataan yang direncanakan oleh masyarakat. baik pengembang maupun masyarakat akan sama-sama mendapat manfaat dari penataan tersebut. Keberadaan ruang terbuka hijau dapat menjadikan kawasan bantaran sungai menjadi lebih baik dari segi estetika dan visual.

2) Masyarakat melakukan perencanaan dan pemasaran produk industri kerajinan dan makanan yang dibantu oleh stakeholder terkait agar dapat bersaing di pasaran/

3) Industri kerajinan dan makanan rutin mengikuti pameran dan pelatihan dalam rangka pengembangan industri untuk meningkatkan kreatifitas produk yang akan dipasarkan.

\section{c. Strategi WO (Weakness - Opportunities) yaitu strategi yang}

disusun dengan melihat kelemahan kawasan prioritas Kelurahan Suryatmajan dengan mempertimbangkan peluang di masa yang akan datang. Strategi WO (Weakness - Opportunities) antara lain:

1) Perlunya program-program penataan lingkungan pemukiman oleh pemerintah maupun swasta agar kawasan bantaran sungai dapat tertata, baik dari segi sarana prasaran, sanitasi, air bersih, akses jalan, tata ruang, rumah layak huni, dan sebagainya. Strategi pemasarannya dengan bazar atau lokakarya yang mengundang pemerintah kota, provinsi, maupun swasta. Kemudian mengajukan proposal kemitraan untuk ditindaklanjuti.

2) Perlunya kegiatan penyuluhan untuk meningkatkan pengetahuan, pemahaman, dan keterampilan masyarakat terkait penataan lingkungan pemukiman, pengolahan sampah, pengelolaan sampah, dan sanitasi. Strategi pemasarannya dengan mengajukan proposal kemitraan yang melibatkan pemerintah daerah, pemerintah pusat, swasta, lembaga swadaya masyarakat, maupun pergururuan tinggi (akademisi).

3) Perlunya balai pertemuan warga sebagai tempat pertemuan rutin masyarakat. Strategi pemasarannya dengan mengajukan proposal kemitraan yang melibatkan pemerintah daerah.

d. Strategi WT (Weakness - Treaths) yaitu strategi yang disusun untuk meminimalkan kelemahan yang ada 
di kawasan prioritas Kelurahan Suryatmajan dan mengurangi hambatan ataupun ancaman di masa yang akan datang. Strategi WT (Weakness - Treaths) antara lain:

1) Perlu adanya kerjasama antara masyarakat dengan pemerintah maupun swasta untuk menata dan memperbaiki lingkungan pemukiman.

2) Perlu adanya kerjasama antara masyarakat dengan pemerintah maupun swasta untuk pengembangan ekonomi masyarakat melalui permodalan dan pelatihan-pelatihan industri rumah tangga.

3) Diperlukan perubahan pola pikir masyarakat tentang pengolahan dan pengelolaan sampah. Tidak boleh lagi membuang sampah langsung ke sungai, sampah organik, kertas, dan plastik yang telah dikelompokkan dapat memiliki nilai ekonomi jika diolah dan dikelola dengan baik.

4) keterampilan yang bersertifikat untuk mengurangi pengangguran.

5) Perlu adanya kerjasama antara masyarakat dan pemerintah terkait mitigasi bencana banjir lahar dingin dan kebakaran.

\section{KESIMPULAN}

Penentuan strategi pemberdayaan masyarakat merupakan tahap awal dari keseluruhan kegiatan pemberdayaan, karena tahap awal dapat menentukan kategori masyarakat setempat dan pola pemberdayaan yang akan dilakukan. Perlu adanya perubahan pola pikir masyarakat tentang penataan lingkungan pemukiman, karena jika lingkungan pemukiman sudah tertata dengan baik, masyarakat juga akan mendapatkan keuntungan. Antara lain seperti kawasan pemukiman dan bantaran sungai tidak terlihat kumuh lagi, sanitasi berfungsi dengan baik, ketersediaan air bersih mencukupi, derajat kesehatan masyarakat meningkat, dan dapat meningkatkan ekonomi masyarakat. Kesiapan pemerintah daerah bersama masyarakat masih diperlukan sebagai upaya membangun masyarakat dan penataan lingkungan setempat agar terjadi sinergitas dan sinkronisasi program.

\section{DAFTAR PUSTAKA}

----------, 2010. Kelurahan Suryatmajan.

Tersedia pada:

www.jogjaprov.go.id, diakses pada 20 Juni 2016.

$\begin{array}{lr}---------, & \text { 2014. Pedoman Teknis } \\ & \text { Penataan r Lingkungan } \\ \text { Permukiman } & \text { Berbasis } \\ \text { Komunitas. } & \text { Jakarta: } \\ \text { Direktorat Jenderal Cipta } \\ \text { Karya Kementerian Pekerjaan } \\ \text { Umum RI. }\end{array}$

Kotler, P. 1989. Social Marketing Strategies for Changing Public Behaviour. New York: The Free Press, A Division of Macmillan, Inc.

Rangkuti, F. 2013. Teknik Membedah Kasus Bisnis Analisis SWOT. Jakarta: PT. Gramedia Pustaka Utama.

Setiana. 2005. Teknik Penyuluhan dan Pemberdayaan Masyarakat. Jakarta: Ghalia Indonesia.

Slamet. 2003. Menata Sistem Penyuluhan Pertanian Menuju Pertanian Modern. Bogor: IPB Press.

Sulistiyani, A.T. 2004. Kemitraan dan Model-Model Pemberdayaan. Yogyakarta: Graha Ilmu. 
Sumardjo. 1999. Transformasi Model

Propinsi Jawa Barat).

Penyuluhan Pertanian

Disertasi. Institut Pertanian

Menuju

Pengembangan

Kemandirian Petani (Kasus

Bogor. 